УДК 616.12-005.8:615.275.4

ОБЗОР

РОЛЬ БИОПРЕПАРАТОВ В ПРОФИЛАКТИЧЕСКОЙ КАРДИОЛОГИИ

\author{
1,2Чаулин А.М., ${ }^{1}$ Григорьева Ю.В.
}

${ }^{1}$ ФББОУ ВО «Самарский государственный медицинский университет» Министерства здравоохранения Российской Федерации, Самара, e-mail: alekseymichailovich22976@gmail.com;

${ }^{2}$ ГБУЗ «Самарский областной клинический кардиологический диспансер», Самара, e-mail: alekseymichailovich22976@gmail.com

Одним из самых перспективных терапевтических и профилактических подходов для ведения пациентов с сердечно-сосудистыми заболеваниями является использование биопрепаратов. К биопрепаратам относятся гормоны, цитокины, интерлейкины, вакцины, моноклональные антитела, интерфероны и ряд других молекул белково-пептидной природы. Биопрепараты обладают значительными преимуществами, по сравнению с традиционно используемыми химическими соединениями, в частности имеют более высокую целевую специфичность, низкий риск лекарственного взаимодействия, более удобный интервал дозирования. В настоящее время немалые успехи были достигнуты в разработке моноклональных антител, направленных на нормализацию липидного обмена и уменьшение воспалительных реакций, которые играют важную роль в развитии и прогрессировании сердечно-сосудистых заболеваний. В частности, в ряде крупных клинических исследований продемонстрирована высокая эффективность моноклональных антител, ингибирующих пропротеиновую конвертазу субтилизин-кексинового типа 9 (PCSK9) в лечении и профилактике развития неблагоприятных сердечно-сосудистых событий. Данные препараты показали высокую эффективность и безопасность и недавно были одобрены для практического использования. Кроме того, большие перспективы имеют моноклональные антитела, являющиеся специфическими антагонистами рецептора IL- $1 \beta$. Использование данных препаратов приводит к снижению активности воспалительных процессов и уменьшению риска развития сердечно-сосудистых заболеваний. В настоящей статье суммированы сведения о роли биопрепаратов в профилактической кардиологии. Значительное внимание уделено обсуждению моноклональных антител против PCSK9 и моноклональных антител, направленных на уменьшение воспалительных реакций, являющихся важным звеном в патогенезе сердечно-сосудистых заболеваний.

Ключевые слова: обзор литературы, биопрепараты, моноклональные антитела, сердечно-сосудистые заболевания, профилактика, ингибиторы PCSK9, антагонисты рецептора Il-1及

\title{
THE ROLE OF BIOLOGICS IN PREVENTIVE CARDIOLOGY
}

\author{
${ }^{1,2}$ Chaulin A.M., ${ }^{1}$ Grigoreva Yu.V.
}

${ }^{1}$ Samara State Medical University, Samara, e-mail: alekseymichailovich22976@gmail.com; ${ }_{2}^{2}$ Samara Regional Cardiology Dispensary, Samara, e-mail: alekseymichailovich22976@gmail.com

One of the most promising therapeutic and preventive approaches for the management of patients with cardiovascular diseases is the use of biologics. Biologics include hormones, cytokines, interleukins, vaccines, monoclonal antibodies, interferons, and a number of other protein-peptide molecules. Biologics have significant advantages in comparison with traditionally used chemical compounds, in particular, they have a higher target specificity, a lower risk of drug interaction, and a more convenient dosage interval. Currently, considerable progress has been made in the development of monoclonal antibodies aimed at normalizing lipid metabolism and reducing inflammatory reactions, which play an important role in the development and progression of cardiovascular diseases. In particular, a number of large clinical studies have demonstrated the high effectiveness of monoclonal antibodies that inhibit the proprotein convertase of subtilisin-kexin type 9 (PCSK9) in the treatment and prevention of adverse cardiovascular events. These drugs have shown high efficacy and safety and have recently been approved for practical use. In addition, monoclonal antibodies that are specific antagonists of the IL-1 $\beta$ receptor have great prospects. The use of these drugs leads to a decrease in the activity of inflammatory processes and a decrease in the risk of developing cardiovascular diseases. This article summarizes the information about the role of biologics in preventive cardiology. Considerable attention is paid to the discussion of monoclonal antibodies against PCSK9 and monoclonal antibodies aimed at reducing inflammatory reactions, which are an important link in the pathogenesis of cardiovascular diseases.

Keywords: literature review, biologics, monoclonal antibodies, cardiovascular diseases, prevention, PCSK9 inhibitors, Il-1ß receptor antagonists

Биопрепараты - это сложные продукты, полученные из природных источников и произведенные с использованием передовых биотехнологий [1]. Моноклональные антитела (от англ. monoclonal antibody, сокращенно mAb) представляют собой класс биопрепаратов, широко используемых для лечения иммунных расстройств, но пока с ограниченным успехом в профилактике или лечении сердечно-сосудистых заболеваний (CC3) [2]. Одним из немногих примеров $\mathrm{mAb}$, доказавших свою эффективность в области кардиологии, является абциксимаб, ингибитор гликопротеина IIb / IIIa, используемый для предотвращения тромбоза во время чрескожных коронарных вмешательств [2]. Ожидается, что эта ситуация скоро изменится после недавнего создания ингибиторов пропротеинконвертазы субтилизин/кексин типа 9 (PCSK9) - 
группы моноклональных антител, разработанных для воздействия на холестерин липопротеинов низкой плотности (LDL-C). Данные препараты к настоящему времени успешно прошли ряд крупномасштабных клинических испытаний [3] и были одобрены для практического использования [4-6]. В настоящее время в профилактической кардиологии основное внимание уделяется лечению и профилактике липидных нарушений, таких как семейная гиперхолестеринемия (СГ) непереносимость статинов [5-7].

Цель настоящей статьи - провести обзор по роли биопрепаратов, в частности моноклональных антител в профилактической кардиологии.

В отличие от традиционных системных лекарственных препаратов, биопрепараты представляют собой сложные белки или олигопептиды, полученные из природных источников и производимые с использованием передовых биотехнологических процессов [1]. Среди биологических продуктов (препаратов) Всемирная организация здравоохранения (BO3) выделяет вакцины, продукты крови для переливания, аллергенные экстракты, человеческие клетки, ткани для трансплантации, генную терапию и клеточную терапию.

Биопрепараты обычно демонстрируют высокую специфичность в отношении своей мишени, связываются в значительной степени на внеклеточном уровне и имеют меньший риск лекарственного взаимодействия, поскольку они не метаболизируются через печеночные или почечные пути (таблица) [2]. Среди используемых в настоящее время биологических терапевтических продуктов можно отметить следующие: моноклональные антитела, гормоны (например, инсулин, паратиреоидный гормон), интерфероны, интерлейкины, белки, пептиды и вакцины [2]. Моноклональные антитела составляют группу биопрепаратов, предназначенных для нацеливания на определенные компоненты клеточных механизмов или путей, и широко используются для лечения онкологических или иммунных заболеваний (таблица) [2]. Моноклональные антитела естественным образом вырабатываются В-клетками и также известны как иммуноглобулины (Ig) с соответствующими подтипами (IgA, IgD, $\operatorname{IgE}, \operatorname{IgG}$ и $\operatorname{IgM})$. Подтип $\mathrm{IgG}$ составляет около $80 \%$ всех антител человека и является наиболее часто используемым классом Ig для создания терапевтических гибридов mAb (В-клетки, слитые с бессмертной линией клеток) [2]. Первоначально производство терапевти- ческих mAb включало инокуляцию мышей заданным антигеном, однако лечение полученным данным образом mAb имело высокий уровень иммуногенности и, следовательно, ограниченную эффективность у пациентов. Изобретение рекомбинантной антигенной инженерии сделало возможным перейти от мышиных mAb к химерным $\mathrm{mAb}$ и в конечном итоге к минимально иммуногенным гуманизированным mAb (>90\% человека). Сегодня технология гибридом XenoMouse позволяет производить полностью человеческие моноклональные антитела, выделенные из селезенки трансгенных мышей, которые продуцируют только человеческие антитела [2].

Терапевтические mAb вводят парентерально (внутривенно, подкожно или внутримышечно). Циркулирующие моноклональные антитела обычно имеют период полужизни 7-21 день и выводятся через фагоцитарные и эндотелиальные клетки ретикулоэндотелиальной системы. Побочные эффекты биологических препаратов на основе $\mathrm{mAb}$ в основном связаны с иммунными реакциями (иммунологическим ответом на вводимые антитела) и аллергическими реакциями в месте инъекции. Однако иммунные реакции значительно уменьшились с появлением полностью человеческих моноклональных антител [2].

\section{Использование тАb в кардиологии}

На сегодняшний день mAb доказали свою эффективность и безопасность в основном при онкологии и иммунных расстройствах. В настоящее время следующие mAb были одобрены для лечения CC3: 1) абциксимаб (ReoPro), ингибитор гликопротеина IIb / IIIa, который используется в качестве адъювантной антитромбоцитарной терапии во время чрескожных коронарных вмешательств у пациентов с ишемической болезнью сердца (ИБС) и острым коронарным синдромом (ОКС); и 2) антитела к дигоксину (Digitalis-Antidote BM), моновалентный фрагмент (Fab-фрагмент), связывающий антитела овечьего Ig, используемый при передозировках и отравлениях дигоксином. Базиликсимаб (Simulect) представляет собой химерное моноклональное антитело мыши и человека к антигену $\mathrm{CD} 25$ ( $\alpha$-цепь поверхностного рецептора IL-2), одобренное для профилактики острого отторжения органа у пациентов, которым проводится трансплантация сердца и почки. Он также используется в острой фазе операций, поскольку некоторые предварительные данные указывают на его эффективность и безопасность после трансплантации сердца $[8,9]$. 
Различия между моноклональными антителами и небольшими химическими молекулами, по [2] с изменениями и дополнениями

\begin{tabular}{|l|l|l|}
\hline & Моноклональные антитела & Небольшие химические молекулы \\
\hline Структура & Иммуноглобулин & Малые молекулы \\
\hline Производство & $\begin{array}{l}\text { Среда для культивирования клеток } \\
\text { (гибридома) }\end{array}$ & Химический синтез \\
\hline Целевая специфичность & Высокая & Низкая \\
\hline Элиминация из кровотока & Ретикулоэндотелиальная система & Печеночные и почечные пути \\
\hline Введение в организм & Парентерально & Перорально и парентерально \\
\hline Лекарственные взаимодействия & Низкие & Потенциально высокие \\
\hline Дозирование & Каждые 1-8 недель & Ежедневно, еженедельно \\
\hline Расходы на производство & Высокие & $\begin{array}{l}\text { Низкие по сравнению с монокло- } \\
\text { нальными антителами }\end{array}$ \\
\hline Основные показания & $\begin{array}{l}\text { Онкология, ревматология, иммуно- } \\
\text { логия, гастроэнтерология }\end{array}$ & Все \\
\hline Основные противопоказания & $\begin{array}{l}\text { Состояние с ослабленным имму- } \\
\text { нитетом; туберкулез; специфично } \\
\text { для отдельных препаратов }\end{array}$ & $\begin{array}{l}\text { Специфичатов } \\
\text { пано для отдельных пре- }\end{array}$ \\
\hline
\end{tabular}

Использование mAb для ингибирования PCSK9 для лечения гиперхолестеринемии и вторичной профилактики сердечно-сосудистых заболеваний, а также для уменьшения воспаления, связанного с ССЗ, обсуждается в нескольких обзорных статьях [5, 7, 10]. PCSK9 связывается с рецептором липопротеинов низкой плотности (LDLR) на поверхности гепатоцитов, тем самым предотвращая рециклинг LDLR и усиливая их деградацию в эндосомах/лизосомaх, что приводит к снижению клиренса LDL-C [11-13]. Многие мутации, усиливающие активность PCSK9, были идентифицированы как генетические маркеры СГ, a мутации потери функции PCSK9 были связаны со снижением уровней LDL-C, а также с более низким риском развития ИБС $[5,14]$. Кроме того, уровни PCSK9 повышаются при терапии статинами, что указывает на роль PCSK9 в резистентности к статинам [5, 11]. Эти данные являются доказательством современной концепции ингибирования PCSK9 при лечении и профилактике гиперхолестеринемии и, соответственно, СС3.

В настоящее время в двойных слепых рандомизированных контролируемых испытаниях (РКИ) проходят испытания три ингибитора PCSK9: алирокумаб, эволокумаб и бокоцизумаб. Алирокумаб и эволокумаб уже показали свою эффективность для лечения пациентов с СГ с плохо контролируемым уровнем LDL-C, несмотря на максимально переносимую терапию статинами [4, 5]. Результаты испытаний показали, что оба моноклональных антитела против PCSK9 систематически снижали уровни LDL-C на 40-70\% по срав- нению с плацебо, одновременно снижая уровни триглицеридов и аполипопротеина В (АроВ) и повышая уровень холестерина липопротеинов высокой плотности (HDL-C) и аполипопротеина A1 (ApoA1) [15-17]. Недавно исследование ODYSSEY Combo показало, что алирокумаб более эффективен, чем эзетимиб, в снижении уровней LDL-C, при этом профиль высокой безопасности наблюдается в обеих группах [18]. В свете этих выводов mAb против PCSK9, по-видимому, подтверждают свою высокую эффективность в качестве гиполипидемических средств у пациентов с СГ, и также потенциально для уменьшения и профилактики риска развития неблагоприятных сердечно-сосудистых событий, как было показано, в исследовательских анализах $[19,20]$. В долгосрочном исследовании ODYSSEY LONG TERM был рандомизирован 2341 пациент с СГ или ИБС, получавший алирокумаб в дозе 150 мг каждые 2 недели по сравнению с плацебо. На 52 неделе прием алирокумаба сопровождался снижением уровня LDL-C на $60 \%$ (среднее значение LDL-C 1,3 ммоль/л при приеме алирокумаба по сравнению с LDL-C 3,1 ммоль/л при плацебо, p <0,001). Согласно исследовательскому анализу, частота выявленных серьезных сердечно-сосудистых заболеваний, требующих госпитализации, составила 1,7\% при приеме алирокумаба по сравнению с 3,3\% при плацебо (отношение рисков [HR]: 0,52, $95 \%$ доверительный интервал [CI]: 0,31-0,90 p=0,02) [19]. В исследовании OSLER, в котором эволокумаб сравнивали со стандартной статиновой терапией, эволокумаб продемонстрировал снижение частоты сердечно-сосудистых 
событий через 1 год $(0,95 \%$ против $2,18 \%$, HR: 0,47, 95\% CI: 0,28-0,27, p=0,003) [20]. В целом профили безопасности mAb сопоставимы с плацебо; однако в группах пациентов, принимающих mAb против PCSK9, было зарегистрировано больше нейрокогнитивных побочных эффектов (0,9\% против $0,3 \%$ для эволокумаба и плацебо, соответственно, значение $\mathrm{p}$ не сообщалось, и $1,2 \%$ против $0,5 \%$ для алирокумаба и плацебо, соответственно, $\mathrm{p}=0,17)[19,20]$. Недавний метаанализ 24 рандомизированных контролируемых испытаний, включивший 10159 пациентов показал значительное снижение смертности от всех причин (HR: 0,45, 95\% CI: 0,23-0,86, p=0,015), смертности от CC3 (OR: 0,50, 95 \% CI: 0,23-1,10, $\mathrm{p}=0,084)$ и смертности от инфаркта миокарда (HR: 0,49, 95\% CI: 0,26-0,93, p =0,030) у пациентов, принимающих mAb против PCSK9 по сравнению со стандартной статиновой терапией [21]. Кроме того, mAb против PCSK9 не усиливали серьезных нежелательных явлений, хотя в этом метаанализе не сообщалось о конкретных нейрокогнитивных событиях [21]. Другой серьезной проблемой может быть демиелинизация центральной нервной системы или лейкоэнцефалопатия. Кроме того, введение $\mathrm{mAb}$ было связано с некоторыми иммунологическими реакциями, такими как анафилаксия, сывороточная болезнь, образование антител против $\mathrm{mAb}$ и синдром высвобождения цитокинов (англ. cytokine release syndrome), потенциально угрожающий жизни [22, 23].

Если терапия PCSK9 продолжит демонстрировать столь впечатляющие эффекты снижения уровня LDL-C, то врачи могут рассчитывать на эффективное дополнение или альтернативу статинам в качестве гиполипидемических средств [24]. К настоящему времени моноклональные антитела против PCSK9 (алирокумаб и эволокумаб) получили одобрение для лечения СГ и пациентов с непереносимостью статинов в США, Европе и России [5, 7]. Другой областью исследования является потенциал mAb против PCSK9 во вторичных условиях для лечения и профилактики дислипидемий после перенесенного ОКС и инфаркта миокарда. Для исследования данных аспектов в два крупномасштабных исследования фазы III были включены пациенты с установленной ИБС для того, чтобы оценить, могут ли ингибиторы PCSK9 снизить частоту сердечно-сосудистых событий у пациентов с высоким риском СС3, таких как госпитализированные по поводу OKC: FOURIER (Further Cardiovascular Outcomes Research with PCSK9 Inhibitors in subjects with Elevated Risk, NCT01764633) для эволокумаба; и ODYSSEY OUTCOMES (Evaluation of Cardiovascular Outcomes After an Acute Coronary Syndrome During Treatment With Alirocumab, SAR236553/ REGN727, NCT01663402) для алирокумаба [25]. Планируется участие более 20000 пациентов в каждом исследовании. Эти крупномасштабные исследования необходимы для оценки долгосрочной безопасности и клинического применения $\mathrm{mAb}$ против PCSK9 [26].

\section{Перспективы борьбы с воспалением при остром коронарном синдроме. исследования CANTOS и CIRT}

Воспаление является основным компонентом атеросклеротического заболевания, включая разрыв бляшки, и, как следствие, приводит к острым СС3, в числе которых следует отметить ОКС [27-29]. Врожденный и приобретенный иммунитет играют ключевую роль в биологии атерогенеза, включая адгезию клеток, трансмиграцию клеток через эндотелий, образование жировых полос, миграцию гладкомышечных клеток, а также прогрессирование и разрыв бляшек [30-32]. При активации пути интерлейкина-1 (IL-1), фактора некроза опухоли- $\alpha$ (TNF- $\alpha)$ или интерлейкина-6 (IL-6) приводят к повышенным уровням белков острой фазы печени, включая $\mathrm{C}$-реактивный белок (CRP), фибриноген и ингибитор активатора плазминогена типа 1 [27]. Эпидемиологические исследования показали, что маркеры воспаления, такие как CRP, IL-6 и TNF- $\alpha$, связаны с последующими неблагоприятными событиями при СС3 независимо от гиперлипидемии и других основных факторов риска CC3 [33, 34]. Учитывая эти факторы воспаления, нацеливание на причинные пути воспаления, а не на один маркер, вероятно, будет наиболее многообещающим подходом для разработки профилактической и неотложной терапии при СС3 [35-37]. Для клиницистов CRP - хорошо известный маркер, используемый в повседневной практике для более точного выявления пациентов с повышенным риском СС3 [38]. Причина, по которой воспаление, как полагают, играет независимую роль в возникновении СС3, частично связана с тем фактом, что половина всех сердечных приступов и инсультов происходит у практически здоровых мужчин и женщин с нормальным уровнем холестерина или с низким риском сердечно-сосудистых заболеваний в соответствии со стратификацией риска [38]. Тем самым подход, направленный на борьбу с воспалением, имеет важные пре- 
имущества независимо от сопутствующей гиполипидемической или антитромбоцитарной терапии.

Инфламмасомы с NOD-подобным peцептором пиринового домена 3 (NLRP-3) играют ключевую роль в продукции нескольких провоспалительных цитокинов, таких как IL-1 $\beta$, после распознавания отложений кристаллов холестерина в растущей атероме [39]. IL-1 $\beta$ продуцируется моноцитами и макрофагами, которые являются ключевыми клетками, участвующими в атеросклерозе. Ананкира (кинерет), антагонист рецептора IL-1 $\beta$, уже показал положительные результаты, заключающиеся в нормализации гликемии и системного воспаления у пациентов с сахарным диабетом [40]. Пилотное исследование фазы II у пациентов с диабетом также показало, что канакинумаб, человеческое mAb, нацеленное на IL$1 \beta$, эффективно снижает уровень IL-6 и CRP (>50\%) [41]. Канакинумаб одобрен для лечения системного ювенильного идиопатического артрита и в настоящее время исследуется у пациентов с ОКС. Исследование CANTOS (Canakinumab Anti-Inflammatory Thrombosis Outcomes, NCT01327846) было проведено для того, чтобы проверить, может ли человеческое $\mathrm{mAb}$, специфически ингибирующее IL-1ß, снизить частоту CC3 у пациентов с высоким риском [42]. Основная цель исследования CANTOS - оценить, снизит ли длительное лечение канакинумабом $(50,150$ или 300 мг каждые 3 месяца) по сравнению с плацебо частоту возникновения СC3 у пациентов, перенесших инфаркт миокарда с коронарной реваскуляризацией и признаками воспаления (hsCRP $>2$ мг/л), несмотря на интенсивную вторичную профилактику. Первичные исходы представляют собой совокупную конечную точку серьезного неблагоприятного CC3, определяемого как инфаркт миокарда, нефатальный инсульт или сердечно-сосудистая смерть. Другими исследовательскими конечными точками будут возникновение событий сердечной недостаточности, фибрилляции предсердий, тромбоза стента и тромбоэмболических событий. Пациенты с ослабленным иммунитетом и пациенты с сердечной недостаточностью, неконтролируемой гипертензией или диабетом, почечной или печеночной недостаточностью и онкологическими заболеваниями будут исключены из исследования. В общей сложности, у 17200 пациентов, рандомизированных для приема канакинумаба в дозе 50 мг, 150 мг, 300 мг или плацебо, обнаружено снижение риска СС3 на 20\% по сравнению с плацебо (все пациенты проходят стандартную терапию, рекомендованную для вторичной профилактики). Что касается безопасности, то особое внимание будет уделено разработке антител к канакинумабу. CANTOS - это первое исследование, основанное на серьезных неблагоприятных сердечно-сосудистых событиях, в котором конкретно рассматривается воспалительная гипотеза атеросклероза.

Второе продолжающееся испытание с использованием метотрексата, небиологического препарата, - это исследование CIRT (Cardiovascular Inflammation Reduction Trial, NCT01594333) среди пациентов с CC3 (в частности, с ОКС и инфарктом миокарда) [43]. В общей сложности 7000 пациентов будут назначены низкие дозы метотрексата, используемые для лечения ревматоидного артрита (15-20 мг в неделю). Метотрексат представляет собой ингибитор дигидрофолатредуктазы, предотвращающий синтез пуриновых и пиримидиновых нуклеотидов, что также составляет основу его использования при лечении злокачественных новообразований. Кроме того, метотрексат может снижать продукцию цитокинов (IL-6, TNF- $\alpha$ ) и иметь несколько эффектов на клеточные механизмы образования атеромы, в связи с чем может также использоваться для лечения и профилактики СС3 [44].

\section{Заключение}

Моноклональныеантитела, по-видимому, открывают самые многообещающие перспективы для разработки новых терапевтических подходов при лечении дислипидемии. К настоящему моменту показано, что MAb против PCSK9 являются хорошим примером эффективного лечения гиперхолестеринемии. Другие появляющиеся моноклональные антитела, направленные на воспаление при сердечно-сосудистых заболеваниях, такие как антагонисты рецептора Il-1 $\beta$ (ананкира, кинерет) или канакинумаб, в настоящее время изучаются в крупномасштабных клинических испытаниях. По сравнению с классическими химическими веществами, биопрепараты обладают преимуществами в виде обеспечения высокой целевой специфичности и меньшего риска лекарственного взаимодействия. В ближайшее время результаты крупных клинических исследований дадут более подробное понимание роли биопрепаратов в профилактической кардиологии, особенно в отношении их долгосрочной эффективности и безопасности.

\section{Список литературы}

1. Morrow T., Felcone L.H. Defining the difference: What Makes Biologics Unique. Biotechnology healthcare. 2004. Vol. 1. No. 4. P. 24-29. 
2. Foltz I.N., Karow M., Wasserman S.M. Evolution and emergence of therapeutic monoclonal antibodies: what cardiologists need to know. Circulation. 2013. Vol. 127. No. 22. P. 2222-2230.

3. Gencer B., Mach F. Sweetless'n low LDL-C targets for PCSK9 treatment. Eur Heart J. 2015. Vol. 36. No. 19. P. $1146-1148$.

4. Gencer B., Lambert G., Mach F. PCSK9 inhibitors Swiss Med Wkly. 2015. Vol. 145. P. w14094. [Electronic resource]. URL: https://pubmed.ncbi.nlm.nih.gov/25856746/ (дата обращения: 11.06.2021).

5. Чаулин А.M., Дупляков Д.В. PCSK-9: современные представления о биологической роли и возможности использования в качестве диагностического маркера сердечно-сосудистых заболеваний. Ч. 1 // Кардиология: новости, мнения, обучение. 2019. Т. 7. № 2. С. 45-57.

6. Чаулин А.М., Дупляков Д.В. PCSK-9: современные представления о биологической роли и возможности использования в качестве диагностического маркера сердечно-сосудистых заболеваний. Ч. 2 // Кардиология: новости, мнения, обучение. 2019. Т. 7. № 4. С. 24-35.

7. Чаулин А.М., Дупляков Д.В. Роль PCSK9 в регуляции транспорта липопротеинов (обзор литературы) // Вопросы биологической, медицинской и фармацевтической химии. 2021. Т. 24. № 1. С. 42-45.

8. Segovia J., Rodriguez-Lambert J.L., Crespo-Leiro M.G., Almenar L., Roig E., Gómez-Sánchez M.A., Lage E., Manito N., Alonso-Pulpón L. A randomized multicenter comparison of basiliximab and muromonab (OKT3) in heart transplantation: SIMCOR study. Transplantation. 2006. Vol. 81. No. 11 P. $1542-1548$.

9. Delgado J.F., Vaqueriza D., Sanchez V., Escribano P. Ruiz-Cano M.J., Renes E., Gómez-Sánchez M.A., Cortina J.M., de la Calzada C.S. Induction treatment with monoclonal antibodies for heart transplantation. Transplant Rev (Orlando). 2011 Vol. 25. No. 1. P. 21-26.

10. Чаулин A.M. Участие пропротеинконвертазы субтилизин кексин типа 9 в патогенезе атеросклероза // Известия высших учебных заведений. Поволжский регион. Медицинские науки. 2020. Т. 1. № 53. С. 111-128.

11. Seidah N.G., Awan Z., Chretien M., Mbikay M PCSK9: a key modulator of cardiovascular health. Circulation research. 2014. Vol. 114. No. 6. P. 1022-1036.

12. Чаулин А.М., Дупляков Д.В. Биомаркеры острого инфаркта миокарда: диагностическая и прогностическая ценность. Ч. 2 (обзор литературы). Клиническая практика. 2020. T. 11. № 4. C. 70-82.

13. Чаулин А.М., Дупляков Д.В. Биомаркеры острого инфаркта миокарда: диагностическая и прогностическа ценность. Ч. 1 // Клиническая практика. 2020. Т. 11. № 3. C. $75-84$.

14. Cohen J.C., Boerwinkle E., Mosley T.H. Jr, Hobbs H.H. Sequence variations in PCSK9, low LDL, and protection agains coronary heart disease. N. Engl. J. Med. 2006. Vol. 354. No. 12 P. $1264-1272$.

15. Sullivan D., Olsson A.G., Scott R., Kim J.B., Xue A., Gebski V., Wasserman S.M., Stein E.A. Effect of a monoclonal antibody to PCSK9 on low-density lipoprotein cholesterol levels in statin-intolerant patients: the GAUSS randomized trial. JAMA. 2012. Vol. 308. No. 23. P. 2497-2506.

16. Giugliano R.P., Desai N.R., Kohli P., Rogers W.J., Somaratne R., Huang F., Liu T., Mohanavelu S., Hoffman E.B., McDonald S.T., Abrahamsen T.E., Wasserman S.M., Scott R., Sabatine M.S.; LAPLACE-TIMI 57 Investigators. Efficacy, safety, and tolerability of a monoclonal antibody to proprotein convertase subtilisin/kexin type 9 in combination with a statin in patients with hypercholesterolaemia (LAPLACE-TIMI 57) a randomised, placebo-controlled, dose-ranging, phase 2 study. Lancet. 2012. Vol. 380. No. 9858. P. 2007-2017.

17. Koren M.J., Scott R., Kim J.B., Knusel B., Liu T., Lei L., Bolognese M., Wasserman S.M. Efficacy, safety, and tolerability of a monoclonal antibody to proprotein convertase subtilisin/kexin type 9 as monotherapy in patients with hypercholesterolaemia (MENDEL): a randomised, double-blind, placebo-controlled, phase 2 study. Lancet. 2012. Vol. 380. No. 9858. P. 1995-2006.

18. Cannon C.P., Cariou B., Blom D., McKenney J.M., Lorenzato C., Pordy R., Chaudhari U., Colhoun H.M.; ODYSSEY COMBO II Investigators. Efficacy and safety of alirocumab in high cardiovascular risk patients with inadequately controlled hypercholesterolaemia on maximally tolerated doses of statins: the ODYSSEY COMBO II randomized controlled trial. Eur Heart J. 2015. Vol. 36. No. 19. P. 1186-1194.

19. Robinson J.G., Farnier M., Krempf M., Bergeron J., Luc G., Averna M., Stroes E.S., Langslet G., Raal F.J., El. Shahawy M., Koren M.J., Lepor N.E., Lorenzato C., Pordy R., Chaudhari U., Kastelein J.J.; ODYSSEY LONG TERM Investigators. Efficacy and safety of alirocumab in reducing lipids and cardiovascular events. N Engl J Med. 2015. Vol. 372. No. 16. P. 1489-1499.

20. Sabatine M.S., Giugliano R.P., Wiviott S.D., Raal F.J., Blom D.J., Robinson J., Ballantyne C.M., Somaratne R., Legg J., Wasserman S.M., Scott R., Koren M.J., Stein E.A.; Open-Label Study of Long-Term Evaluation against LDL Cholesterol (OSLER) Investigators. Efficacy and safety of evolocumab in reducing lipids and cardiovascular events. N Engl J Med. 2015. Vol. 372. No. 16. P. 1500-1509.

21. Navarese E.P., Kolodziejczak M., Schulze V., Gurbel P.A., Tantry U., Lin Y., Brockmeyer M., Kandzari D.E., Kubica J.M., D'Agostino R.B. Sr, Kubica J., Volpe M., Agewall S., Kereiakes D.J., Kelm M. Effects of Proprotein Convertase Subtilisin/Kexin Type 9 Antibodies in Adults With Hypercholesterolemia: A Systematic Review and Meta-analysis. Ann Intern Med. 2015. Vol. 163. No. 1. P. 40-51.

22. Hansel T.T., Kropshofer H., Singer T., Mitchell J.A., George A.J. The safety and side effects of monoclonal antibodies. Nature reviews. Drug Discov. 2010. Vol. 9. No. 4. P. 325-338.

23. Guan M., Zhou Y., Sun J., Chen S. Adverse Events of Monoclonal Antibodies Used for Cancer Therapy. Biomed Research International. 2015. P. 428-169.

24. Vogel RA. PCSK9 inhibition: the next statin? J Am Coll Cardiol. 2012. Vol. 59. No. 25. P. 2354-2355.

25. Schwartz G.G., Bessac L., Berdan L.G., Bhatt D.L., Bittner V., Diaz R., Goodman S.G., Hanotin C., Harrington R.A., Jukema J.W., Mahaffey K.W., Moryusef A., Pordy R., Roe M.T., Rorick T., Sasiela W.J., Shirodaria C., Szarek M., Tamby J.F., Tricoci P., White H., Zeiher A., Steg P.G. Effect of alirocumab, a monoclonal antibody to PCSK9, on long-term cardiovascular outcomes following acute coronary syndromes: rationale and design of the ODYSSEY outcomes trial. Am Heart J. 2014. Vol. 168. No. 5. P. 682-689.

26. Catapano A.L., Papadopoulos N. The safety of therapeutic monoclonal antibodies: implications for cardiovascular disease and targeting the PCSK9 pathway. Atherosclerosis. 2013. Vol. 228. No. 1. P. 18-28.

27. Ridker P.M. Targeting inflammatory pathways for the treatment of cardiovascular disease. Eur Heart J. 2014. Vol. 35. No. 9. P. $540-543$.

28. Chaulin AM, Grigoreva YuV, Duplyakov DV. About the role of immuno-inflammatory mechanisms in the pathogenesis of atherosclerosis. European Journal of Natural History. 2020. No. 5. P. $2-6$

29. Чаулин А.М., Григорьева Ю.В., Дупляков Д.В. Современные представления о патофизиологии атеросклероза. Ч. 1. Роль нарушения обмена липидов и эндотелиальной дисфункции (обзор литературы) // Медицина в Кузбассе. 2020. № 2. C. 34-41.

30. Libby P. Mechanisms of acute coronary syndromes and their implications for therapy. N. Engl. J. Med. 2013. Vol. 368. No. 21. P. 2004-2013.

31. Чаулин А.М., Григорьева Ю.В., Суворова Г.Н., Дупляков Д.В. Способы моделирования атеросклероза 
у кроликов // Современные проблемы науки и образования 2020. № 5. [Электронный pecypc]. URL: http://science-education.ru/ru/article/view?id=30101 (дата обращения: 03.03.2020).

32. Чаулин А.М., Григорьева Ю.В., Дупляков Д.В. Роль толл-подобных рецепторов (tlr) в патогенезе атеросклероза // Международный журнал прикладных и фундаментальных исследований. 2020. № 9. С. 54-58.

33. Rodondi N., Marques-Vidal P., Butler J., SuttonTyrrell K., Cornuz J., Satterfield S., Harris T., Bauer D.C., Ferrucci L., Vittinghoff E., Newman A.B. Health, Aging, and Body Composition Study. Markers of atherosclerosis and inflammation for prediction of coronary heart disease in older adults. Am J Epidemiol. 2010. Vol. 171. No. 5. P. 540-549.

34. Cesari M., Penninx B.W., Newman A.B., Kritchevsky S.B., Nicklas B.J., Sutton-Tyrrell K., Rubin S.M., Ding J., Simonsick E.M., Harris T.B., Pahor M. Inflammatory markers and onset of cardiovascular events: results from the Health $\mathrm{ABC}$ study. Circulation. 2003. Vol. 108. No. 19. P. 2317-2322.

35. Ridker P.M. Testing the inflammatory hypothesis of atherothrombosis: scientific rationale for the cardiovascular inflammation reduction trial (CIRT). J. Thromb. Haemost. 2009. Vol. 7 (Suppl. 1): 332-339.

36. Чаулин А.М., Григорьева Ю.В. Воспаление при атеросклерозе: от теории к практике // Бюллетень науки и практики. 2020. Т. 6. № 10. С. 186-205.

37. Чаулин А.М., Григорьева Ю.В. Сиртуины и сосудистое старение. Международный журнал прикладных и фундаментальных исследований. 2020. № 12. С. 49-54.

38. Goff D.C., Jr., Lloyd-Jones D.M., Bennett G., Coady S., D'Agostino R.B., Gibbons R., Greenland P., Lackland D.T. Levy D., O’Donnell C.J., Robinson J.G, Schwartz J.S., Shero S.T., Smith S.C. Jr, Sorlie P., Stone N.J, Wilson P.W., Jordan H.S., Nevo L., Wnek J., Anderson J.L., Halperin J.L., Albert N.M., Bozkurt B., Brindis R.G., Curtis L.H., DeMets D., Hochman J.S., Kovacs R.J., Ohman E.M., Pressler S.J., Sellke F.W., Shen W.K., Smith S.C. Jr, Tomaselli G.F.; American College of Cardiology / American Heart Association Task
Force on Practice Guidelines. 2013 ACC/AHA guideline on the assessment of cardiovascular risk: a report of the American College of Cardiology/American Heart Association Task Force on Practice Guidelines. Circulation. 2014. Vol. 129. No. 25. Suppl. 2. P. S49-73.

39. Duewell P., Kono H., Rayner K.J., Sirois C.M., Vladimer G., Bauernfeind F.G., Abela G.S., Franchi L., Nuñez G., Schnurr M., Espevik T., Lien E., Fitzgerald K.A., Rock K.L., Moore K.J., Wright S.D., Hornung V., Latz E. NLRP3 inflammasomes are required for atherogenesis and activated by cholesterol crystals. Nature. 2010. Vol. 464. No. 7293. P. 1357-1361.

40. Larsen C.M., Faulenbach M., Vaag A., Vølund A., Ehses J.A., Seifert B., Mandrup-Poulsen T., Donath M.Y. Interleukin-1-receptor antagonist in type 2 diabetes mellitus. N Engl. J. Med. 2007. Vol. 356. No. 15. P. 1517-1526.

41. Ridker P.M., Howard C.P., Walter V., Everett B., Libby P., Hensen J., Thuren T; CANTOS Pilot Investigative Group. Effects of interleukin-1beta inhibition with canakinumab on hemoglobin A1c, lipids, C-reactive protein, interleukin-6, and fibrinogen: a phase IIb randomized, placebo-controlled trial. Circulation. 2012. Vol. 126. No. 23. P. 2739-2748.

42. Ridker P.M., Thuren T., Zalewski A., Libby P. Interleukin-1beta inhibition and the prevention of recurrent cardiovascular events: rationale and design of the Canakinumab Anti-inflammatory Thrombosis Outcomes Study (CANTOS). Am Heart J. 2011. Vol. 162. No. 4. P. 597-605.

43. Everett B.M., Pradhan A.D., Solomon D.H., Paynter N., Macfadyen J., Zaharris E., Gupta M., Clearfield M., Libby P., Hasan A.A., Glynn R.J., Ridker P.M. Rationale and design of the Cardiovascular Inflammation Reduction Trial: a test of the inflammatory hypothesis of atherothrombosis. Am Heart J. 2013. Vol. 166. No. 2. P. 199-207. e115.

44. Gerards A.H., de Lathouder S, de Groot E.R., Dijkmans B.A., Aarden L.A. Inhibition of cytokine production by methotrexate. Studies in healthy volunteers and patients with rheumatoid arthritis. Rheumatology (Oxford). 2003. Vol. 42. No. 10. P. 1189-1196. 